\title{
Hepatic scintillography
}

Since hepatic scintillography was first introduced in $1953,{ }^{1}$ this technique has been extensively applied to the investigation of patients with liver diseases. After the intravenous injection of a gammaemitting isotope which is selectively taken up by the liver, the organ is scanned with a collimated scintillation probe, the output of which is converted into suitably selected electrical impulses, which are plotted either as dots on paper or by a photo recording device. ${ }^{2}$ The various settings of the scanning equipment must be appropriately standardized before any meaningful comparison of different scans can be made.

Compounds used for hepatic scintillography fall into two groups: those which are taken up by the Kupffer cells and those which are taken up by the liver cells. Compounds in the first group are all in colloidal form. Intravenously administered colloids are taken up by cells of the reticuloendothelial system, the exact distribution depending on the sizes of the colloid particles. ${ }^{4}$ When the particle size is $5-1,000 \mathrm{~m} \mu$. almost all of the injected dose is taken up by the Kupfer cells in normal subjects. ${ }^{2,4}$ In disease states uptake of colloid will be influenced by changes in hepatic blood flow and in the number and function of the Kupffer cells. The first compound of this type, which was used for liver scanning, was ${ }^{131}$ I-labelled albumin, but this compound, given in an aggregated form, has the major disadvantage that hepatic radioactivity declines rapidly due to proteolysis and liberation of inorganic ${ }^{131}$ I by the Kupffer cells. ${ }^{5}$ Radiocolloidal gold $\left({ }^{198} \mathrm{Au}\right)$ does not have this disadvantage and has been extensively used.$^{5,6,7,8}$ The colloid is retained in the Kupffer cells and hepatic radioactivity declines slowly according to the rate of physical decay of the isotope. The synthetic isotope technetium $\left({ }^{99 \mathrm{~m}} \mathrm{Tc}\right)$, prepared in the form of a colloidal sulphide, is similarly retained. However, in contrast to ${ }^{198} \mathrm{Au}$, which emits both gamma $(410 \mathrm{Kev})$ and beta rays and has a half life of 2.7 days, ${ }^{99 \mathrm{~m} T c}$ emits exclusively gamma rays $(140 \mathrm{Kev})$ and has a half life of only six hours. Thus, by using ${ }^{99 \mathrm{~m}} \mathrm{Tc}$ larger doses of activity can be given, enabling higher count rates, faster scanning speeds and better collimation to be obtained for less radiation dosage to the patient. ${ }^{99 \mathrm{~m}} \mathrm{Tc}$ is probably the agent of choice for routine liver scanning at the present time, ${ }^{9,10,11}$ although the requirement that it be freshly prepared by elution from its parent isotope $\left({ }^{99} \mathrm{molybdenum}\right)$ is a disadvantage. The radiation hazard is small. The dose to the liver from a scan using $1 \mathrm{mci}{ }^{99 \mathrm{~m}} \mathrm{Tc}$ is less than $1 \mathrm{rad}$.

Compounds in the second group, after being taken up by the liver cells, are subsequently excreted via the bile and intestine. During the period of scanning the distribution of activity in the liver may change markedly and concentration of activity may occur in the gall bladder. ${ }^{2}$ Thus artefacts are more likely. In the presence of either reduced hepatic blood flow or impaired liver cell function, hepatic uptake of these compounds is impaired, activity is often seen in the position of the kidneys, and there is increased urinary excretion of activity. ${ }^{12}{ }^{131}$ I Rose Bengal has been the most widely used compound in this group, $5,12,13,14$. Recently, a newly synthesized compound, 131I-labelled bromsulphthalein ( ${ }^{131}$ I B.S.P.), has been used. In contrast to ${ }^{131}$ I Rose Bengal, this compound is metabolized by the liver cell, it is chemically pure, and the iodine atoms are not readily dissociated from the molecule. ${ }^{15,16}$ However, ${ }^{131}$ I B.S.P. does not appear to have any marked advantages over ${ }^{131}$ I Rose Bengal for routine liver scanning. ${ }^{17}$ Because they are excreted in the bile, serial scans after the administration of one of these compounds have been used as a diagnostic test in the differential diagnosis of jaundice ${ }^{12}$, but it seems unlikely that such information will usually be any more definitive than that obtainable from other conventional methods.

In general, the appearances of scans of normal livers using compounds taken up by Kupffer cells and compounds taken up by the liver cells are similar, the activity recorded being greatest over the right lobe where hepatic tissue is thickest. There is considerable variation in the normal scan image ${ }^{5}$ but scans are of value in diagnosing anatomical variations of the liver such as a Riedel's 
lobe. By marking the position of the costal margin and any palpable viscera or masses and superimposing the scan on a radiograph, displacements of the liver can be recognized and the relationship of the liver to neighbouring structures can be assessed. Considerable disparity between the upper margin of the scan image and the right hemidiaphragm may be a valuable indication of the presence of a subphrenic lesion, such as an abscess. ${ }^{5,18}$

The main application of hepatic scintillography has been the detection of intrahepatic spaceoccupying lesions, in particular primary and secondary neoplasia, abscesses, and hydatid disease $\mathbf{5 , 6 , 7 , 1 3 , 1 9 , 2 0 , 2 1}$. These are revealed by a zone of diminished or absent uptake of activity, due to a paucity or hypofunction of cells which selectively take up the isotope in the lesion. No inferences as to the likely nature of a space-occupying lesion can be made from the scan image alone, and defects indistinguishable from those produced by space-occupying lesions may occur as a result of infiltrations of the liver such as $\mathrm{fat}^{5}$ or extrahepatic tumours ${ }^{22}$. A lateral scan in addition to the usual antero-posterior scan increases the proportion of intrahepatic space-occupying lesions which are detected by scintillography and permits more accurate localization of the lesions. Such information can be particularly useful in planning appropriate surgical treatment. Space-occupying lesions greater than $2.5 \mathrm{~cm}$. diameter can usually be detected. ${ }^{5}$ The main factors limiting the degree of resolution are respiratory movements, the thickness of the hepatic tissue, and the depth of the lesion. The technique may nevertheless be more valuable than laparotomy ${ }^{13}$ or routine liver function tests $^{23}$ in excluding space-occupying lesions of the liver. Serial scans enable the response to therapy of space-occupying lesions, such as amoebic abscesses and hydatid cysts, ${ }^{7}$ and regeneration after partial hepatectomy ${ }^{24}$ to be followed.

It is possible that scans using compounds taken up by Kupffer cells and those using compounds taken up by liver cells might show marked differences in patients with hepatomas. Comparisons of scans using radiocolloidal gold have been made with those using ${ }^{131}$ I Rose Bengal and ${ }^{131}$ I B.S.P. in the same patients with hepatomas. The differences observed were slight, suggesting that such comparisons will not usually be of diagnostic value. ${ }^{17,25}$

In patients suspected of having intrahepatic space-occupying lesions a scan should be performed routinely before biopsying the liver or needling for pus, as the most appropriate site for these procedures may be indicated. However, it is desirable to have additional clinical and radiological information indicating the probable nature of the lesion to reduce the likelihood of performing liver biopsies on patients with hydatid disease or hepatic haemangiomata.

In patients with chronic hepatocellular disease, such as cirrhosis, ${ }^{3}$ uptake of activity by the liver is often reduced and largely perihilar in distribution. A patchy appearance may be produced, due to statistical variations in the count rate, which may simulate multiple small space-occupying lesions. A greater proportion of an injected dose of a radio-colloid is usually taken up by extrahepatic elements of the reticuloendothelial system, in particular by the spleen. ${ }^{3}$ This phenomenon appears to be relatively greater in chronic hepatocellular disease than in most other diseases which cause hepatosplenomegaly, probable exceptions being sarcoidosis ${ }^{5}$ and bilharzia. ${ }^{26}$ Nevertheless it may be valuable additional evidence in support of a diagnosis of cirrhosis. The degree of splenic uptake of radiocolloid in cirrhotics is probably related to the magnitude of the portal-systemic collateral circulation. ${ }^{27}$ Liver scans in the Budd-Chiari syndrome often show diminished uptake of activity by most of the liver except for a zone near the midline. ${ }^{17}$ This pattern may be due to an appreciably diminished blood flow to all lobes except the caudate, the venous drainage of which tends to be relatively well preserved. ${ }^{28}$

Some of the principles and limitations of hepatic scintillography have been described. It is an important ancillary investigation and when used in conjunction with other clinical, laboratory and radiological evidence can undoubtedly provide valuable diagnostic information. More extensive application and critical appraisal of the technique is required to clarify further its value in the diagnosis and management of patients with diseases which affect the liver. 
${ }^{1}$ Stirrett, L. A., Yuhl, E. T., and Libby, R. L. (1953). A new technique for the diagnosis of carcinoma metastatic to the liver. Surg. Gynec. Obstet., 96, 210-214.

2Sorensen, L. B. (1964). Radioisotope scanning in the diagnosis of liver disease. Biochem. Clin., 3, 47-53.

${ }^{3}$ Christie, J. H., MacIntyre, W. J., Gomez Crespo, G., and Koch-Weser, D. (1963). Radioisotope scanning in hepatic cirrhosis. Radiology, 81, $455-469$.

'Dobson, E. L., and Jones, B. H. (1952). The behaviour of intravenously injected particulate material. Acta med. scand., suppl. 273.

'McAfee, J. G., Ause, R. G., and Wagner, H. N., Jr. (1965). Diagnostic value of scintillation scanning of the liver. Arch. intern. Med., 116, 95-1 10.

'Baum, S., Silver, L., and Vouchides, D. (1966). The recognition of hepatic metastases through radioisotope color scanning. J. Amer. med. Ass., $197,675-679$.

${ }^{7}$ Czerniak, P. (1964). Scanning study of 700 livers. Evaluation of existing diagnostic procedures. In Medical Radioisotope Scanning, vol. 2, pp. 401430. International Atomic Energy Agency, Vienna.

${ }^{8}$ Whang, K. S., Fish, M. B., and Pollycove, M. (1965). Evaluation of hepatic photoscanning with radioactive colloidal gold. J. nucl. Med., 6, 494-505.

'Patton, D. D., Garcia, E. N., and Webber, M. M. (1966). Simplified preparation of technetium 99m sulphide colloid for liver scanning. Amer. J. Roentgenol., 97, 880-885.

${ }^{10}$ Stern, H. S., McAfee, J. G., and Subramanian, G. (1966). Preparation, distribution and utilization of technetium-99m-sulfur colloid. J. nucl. Med., 7, 665-675.

${ }^{11}$ Larson, S. M., and Nelp, W. B. (1966). Radiopharmacology of a simplified technetium-99m-colloid preparation for photoscanning. Ibid., 7, 817-826.

${ }^{12}$ Eyler, W. R., Schuman, B. M., Du Sault, L. A., and Hinson, R. E. (1965). The radioiodinated rose bengal liver scan as an aid in the differential diagnosis of jaundice. Amer. J. Roentgenol., 94, 469-476.

${ }^{13}$ Nagler, W., Bender, M. A., and Blau, M. (1963). Radioisotope photoscanning of the liver. Gastroenterology. 44, 36-43.

"Achaval, A., Tauxe, W. N., and Gambill, E. E. (1965). Scintillation scanning of the liver. Mayo Clin. Proc., 40, 206-215.

${ }^{16} \mathrm{Jirsa}$, M., and Raban, P. (1962). Metabolism of rose bengal. Nature (Lond.), 195, 1100-1101.

18 - , and Billing, B. (1967). Unpublished data.

${ }^{17}$ Jones, E. A., and Jirsa, M. (1967). Hepatic scintillography with special reference to the use of ${ }^{131} \mathrm{I}$ bromsulphthalein. In Proceedings of the Colston Research Society Symposium on the Liver. Blackwell, Oxford.

${ }^{18}$ Bodon, G. R., and Holzwasser, G. R. (1964). The localization of right subphrenic abscess with liver scan. Surg. Gynec. Obstet., 119, 601-602.

${ }^{19}$ Corey, K. R., and Benua, R. S. (1966). Progress in radioisotope scanning. Med. Clin. N. Amer., 50, 689-700.

${ }^{20}$ Doxiades, T., Gatsou, P., Ikkos, D., Merikas, G., and Nastou, A. (1964). The value of liver scanning in the diagnosis of Echinococcus disease of the liver. In Medical Radioisotope Scanning. vol. 2, pp. 389-400. International Atomic Energy Agency, Vienna.

${ }^{21}$ Johnson, P. M., and Grossman, F. M. (1965). Radioisotope scanning in primary carcinoma of the liver. Radiology, 84, 868-872.

22O'Donnell, T. A. (1963). Liver scanning for extrahepatic tumors. Amer. J. Roentgenol., 90, 1063-1067.

${ }^{28}$ Gollin, F. F., Sims, J. L., and Cameron, J. R. (1964). Liver scanning and liver function tests. J. Amer. med. Ass., 187, $111-116$.

24Parker, J. J., and Siemsen, J. K. (1967). Liver regeneration following hepatectomy, evaluated by scintillation scanning. Radiology, 88, 342-344.

${ }^{25}$ Wagner, H. N., Jr., McAfee, J. G., and Mozley, J. M. (1961). Diagnosis of liver disease by radioisotope scanning. Arch. intern. Med., 107, 324-334.

${ }^{26}$ Mustafa, A. G., Razzak, M. A., Mahfouz, M., and Guirgis, B. (1966). Radioisotope photoscanning of the liver in bilharzial hepatic fibrosis. J. nucl. Med., 7, 909-916.

${ }^{27}$ Castell, D. O., and Johnson, R. B. (1966). The ${ }^{108} \mathrm{Au}$ liver scan. An index of portal-systemic collateral circulation in chronic liver disease. New Engl. J. Med., 275, 188-192.

${ }^{28}$ Hales, M. R., and Scatliff, J. H. (1966). Thrombosis of the inferior vena cava and hepatic veins (Budd-Chiari syndrome). Ann. intern. Med. $65,768-781$. 